\title{
ESCOLAS DE FORMAÇÃO NAS ARTES DO CINEMA: UM ESTUDO SOBRE O POLO CINEMATOGRÁFICO DE PAULÍNIA/SP
}

\author{
Cleber Fernando Gomes \\ Universidade Federal de São Paulo/UNIFESP \\ Orientadora: Profa. Dra. Marina Soler Jorge \\ Pesquisa de Mestrado em História da Arte com bolsa FAPESP \\ clebergom@hotmail.com / 19996242982
}

A pesquisa faz uma análise sobre a existência de duas escolas de formação nas artes do cinema, localizadas dentro do Polo Cinematográfico da cidade de Paulínia, no interior do Estado de São Paulo. O objetivo principal foi levantar dados sobre as atividades dessas escolas, assim como, analisar posteriormente a relevância da formação em cursos e oficinas voltados para o campo do cinema brasileiro. O Polo Cinematográfico de Paulínia/SP, foi inaugurado no ano de 2008, idealizado pela Secretaria de Cultura do Município, sendo responsável, desde então, pela produção de diversos filmes brasileiros que, conseguiram atingir projeções nacionais e internacionais. Dessa forma, salientamos a importância de pesquisar, analisar e compreender as ações dessas duas escolas de artes em cinema, direcionadas para a formação de crianças, adolescentes e adultos, uma vez que esse fenômeno poderá contribuir para fortalecer o campo cultural cinematográfico no Brasil, e oferecer aos envolvidos, uma nova oportunidade de atuação profissional e de conhecimentos significativos que vão agregar novos valores para o desenvolvimento pessoal e educacional. A escola, Paulínia Magia do Cinema, subordinada à Secretaria de Cultura, tem como objetivo a formação e qualificação da mão de obra especializada no campo cultural cinematográfico brasileiro, formando profissionais em diversas áreas do cinema, desde a pré-produção, a produção e, pós-produção em audiovisual. E a escola, Paulínia Stop Motion, subordinada à Secretaria de Educação, tem como objetivos, estimular a nova geração para o conhecimento e a prática da arte direcionada a indústria cinematográfica, através de um projeto em parceria com a multinacional dinamarquesa LEGO. Nesse caso, podemos considerar com base em uma pesquisa de campo e bibliográfica que, as duas escolas, quando em pleno funcionamento, tem a capacidade de oferecer a sociedade, ações educativas essenciais para o desenvolvimento das habilidades e competências de futuros cidadãos conscientes e produtivos, seja em âmbito profissional ou social. 
A educação formal no Brasil e no mundo está passando por diversas transformações em busca de novas alternativas para conviver com os avanços de uma nova era repleta de novidades a cada dia. As ciências, em sua ampla gama de diversidade contribui para as mutações da sociedade, alterando os costumes e modos de vida de milhares de indivíduos e grupos. O desenvolvimento constante das Tecnologias da Informação e Comunicação (TICs) são uma realidade que precisam ser enfrentadas com novas propostas para a inclusão e acesso as mais diversas formas de educação, sejam elas, formal, não formal e informal. Para Paulo Freire (1983), “o mundo humano é, desta forma, um mundo de comunicação" (FREIRE, 1983, p.44).

A partir dessa perspectiva, este trabalho levantou dados que materializam essa realidade existente atualmente na sociedade contemporânea, principalmente pelo fenômeno cinematográfico que, surpreende a cada novo lançamento de filme com todas as suas evoluções tecnológicas. As duas escolas de cinema analisadas nesse trabalho, revelam a importância de uma formação contínua no campo cultural, por causa dos seus resultados no campo econômico, profissional e educacional.

O cinema está inserido, desde a sua criação, na história da educação mundial e, posteriormente na história das escolas brasileiras, principalmente nas décadas de 1920 a 1930, com a criação do Instituto Nacional de Cinema Educativo (INCE). Nesse caso, arte e educação são dois fenômenos que caminham juntos na história da humanidade, favorecendo os processos de relações, criação e trocas de conhecimentos (CATELLI, 2010).

Sobre responsabilidade da Secretaria da Cultura, a escola Paulínia Magia do Cinema, tem como objetivo principal, oferecer cursos para o desenvolvimento técnico e profissional em diversos setores do audiovisual, desde a pré-produção, a produção e, a pós-produção de obras cinematográficas. A escola Paulínia Stop Motion, atende um público diferenciado, direcionando seus cursos de acordo com critérios da Secretaria de Educação do Município da cidade de Paulínia, nesse caso, o objetivo é priorizar a participação e o desenvolvimento de crianças e jovens adolescentes que estão matriculados em escolas públicas da cidade. O projeto tem como foco o cinema de animação, em parceria com a multinacional do setor de brinquedos e jogos infantojuvenis, a empresa dinamarquesa LEGO.

Os resultados dessas duas escolas, primeiro, pode ser observado pela alta procura por cursos e oficinas em seus espaços, assim como, o número de participantes em suas atividades, principalmente na escola Paulínia Stop Motion, que continua ativa, 
recebendo alunos da rede pública municipal de ensino. Outro resultado positivo, é observado nos produtos audiovisuais produzidos na escola que conseguem atingir público em Mostras e Festivais de cinema de animação. No caso específico da escola Paulínia Magia do Cinema, seus formandos já conseguiram acesso de trabalhos em produções cinematográficas realizadas no próprio Polo Cinematográfico de Paulínia.

A escola Paulínia Magia do Cinema, que está subordinada à Secretaria de Cultura do Município, tem como foco a criação e o desenvolvimento de cursos e oficinas voltados para o aperfeiçoamento técnico e profissional de jovens e adultos que queiram ingressar no mundo do trabalho dos setores cinematográficos. Mesmo estando temporariamente desativada no ano de 2015, podemos observar que no decorrer de sua história, a escola já ofereceu cursos nas diversas modalidades do cinema, principalmente tendo como objetivo, criar mão de obra qualificada para atender a demanda de profissionais, para exercer funções dentro do próprio Polo Cinematográfico da cidade. Porém, a criação da escola e seus cursos não se baseiam somente em desenvolver mão de obra de pessoas interessadas em trabalhar no próprio Polo Cinematográfico, um dos objetivos da Secretaria Municipal de Cultura é fomentar a economia do município através do turismo cinematográfico gerado pelo próprio complexo de estúdios e escolas.

Em análise ao vídeo de inauguração da escola, realizado no ano de 2007, observamos alguns dados destacados, naquele momento, pela Secretária de Cultura, Tatiana Stefani Quintella, enfatizando a importância da escola Magia do Cinema. Na ocasião, foram mencionados uma alta procura por vagas nos cursos da escola que estava sendo inaugurada, nesse caso, 1740 inscrições foram realizadas para preencher 440 vagas e, posteriormente selecionar 90 estudantes da escola Magia do Cinema para estagiar em 9 produções cinematográficas contempladas por lei de incentivo.

No decorrer dos anos de atuação da escola Paulínia Magia do Cinema, houve diversos impasses políticos com a ativação e desativação de suas atividades. Porém, nos registros de sua breve história, a escola contou com a realização de diversos cursos profissionalizantes, ministrados em parcerias com professores do Senac e da FGV, nas áreas de direção, roteiro, interpretação, produção, além de outros cursos voltados para o desenvolvimento e criação de cinema. A importância desse tipo de escola é valorizada a partir da realidade observada do fenômeno do cinema como indústria com capacidade de geração de emprego e desenvolvimento social, econômico e cultural de uma determinada região, e principalmente pela capacidade de oferecer à homens e mulheres, 
a oportunidade de conhecimento e experiências em áreas de trabalho e cultura que, até então, estavam disponíveis a uma certa elite escolarizada e com poder econômico.

Essa capacidade de conhecer o mundo através de novas oportunidades de trabalho, sejam elas oferecidas pelo cinema, ou por outras formas de relações sociais, é significativamente necessário em uma sociedade que prioriza a educação e o domínio de técnicas do fazer. O domínio do campo cultural pode ser um meio de transformação para homens e mulheres se lançarem na busca por novos horizontes do aprender a conhecer, a conviver, a fazer, e essencialmente, aprender a ser. O mundo do cinema pode ser um dos caminhos.

A escola Paulínia Stop Motion está vinculada à Secretaria de Educação e, desenvolve um trabalho com cursos voltados para o público da educação básica, desde a faixa etária da educação infantil, até aos adolescentes do ensino médio. A escola tem como objetivo inserir os alunos da rede pública de ensino do município, no universo do cinema, através do aprendizado das técnicas de criação cinematográfica, nesse caso, voltadas ao cinema de animação, proporcionando uma vivência semiprofissional no espaço físico da escola que simula uma produtora de cinema.

A oportunidade de conhecer e experimentar coisas novas, transforma a vida desses alunos quando estão em contato com o mundo da criação e produção de cinema. Nesse caso, observamos que as experiências dessa escola de cinema de animação, utilizando as técnicas do Stop Motion, conseguiram despertar o interesse de diversas crianças e jovens das escolas públicas do município, indo mais longe com suas ações, uma vez que despertou também o interesse e a demanda de alunos das escolas privadas da cidade de Paulínia.

Através da parceria com a LEGO, usando os blocos de montar da multinacional, foi possível criar um espaço para desenvolver cursos com crianças da educação infantil, uma ação importante para o despertar da criatividade e do interesse, desde a infância, para criação e produção de cinema. Nesses cursos, voltados para o público infantil, a escola adaptou as aulas para conseguir transmitir os conteúdos e valorizar suas iniciativas. Esses espaços de aprendizado em cinema estão direcionados para as várias etapas da produção cinematográfica, assim como, a elaboração de roteiro, as experiências na direção, produção executiva, foley (sons criados em estúdios) e trilha sonora, design e animação. Todas essas áreas existentes na produção de cinema estão disponíveis na escola Paulínia Stop Motion. É importante destacar que a escola desenvolve um projeto de ensino e inclusão da robótica através de um curso que 
estimula a criação e o desenvolvimento de um protótipo com o uso de peças LEGO, em uma Sala Aberta de Robótica, específica para alunos do $9^{\circ}$ ano. Essa iniciativa é essencial para estimular o "pensamento computacional" tão desejado nos dias atuais dentro das escolas públicas, pois ciência e tecnologia avançam vertiginosamente e tornam-se primordiais para a evolução do país (RAMOS, 2014).

No senso comum, pensamos o cinema como fonte de entretenimento e lazer, porém, a considerada sétima arte é, resultado de pesquisas científicas e do avanço e desenvolvimento tecnológico. Dessa forma, ao inserirmos o cinema dentro das atividades curriculares para alunos da educação básica, estamos contribuindo para que esses alunos aprendam ciência e tecnologia de forma lúdica e animada, despertando nesses futuros profissionais a importância de valorizar a pesquisa científica, principalmente nos alunos de escolas públicas que, convivem com as dificuldades e descasos políticos com a educação. Para Cezar Migliorin, professor de comunicação da Universidade Federal Fluminense-UFF, “não há ensino de cinema que também não seja em si um processo de emancipação" (MIGLIORIN, 2014, p.2).

Outras iniciativas da Prefeitura Municipal de Paulínia, são necessárias para o funcionamento pleno dessas duas escolas de formação nas artes do cinema. Primeiramente, prover essas unidades de professores qualificados para o exercício do ensino no campo cinematográfico, principalmente porque a escola, Paulínia Stop Motion, atualmente no segundo semestre do ano de 2015, está com defasagem de professores para atender a demanda da escola, fazendo com que, muitas salas de aulas fiquem vazias, uma vez que existe a possibilidade de atender mais de mil alunos da rede pública de ensino da cidade. E ainda, acelerar a reestruturação da escola, Paulínia Magia do Cinema, para oferecer a população de jovens e adultos da cidade, a oportunidade de formação em cursos no campo cinematográfico. Segundo Paulo Freire (1983), “o homem, como um ser de relações, desafiado pela natureza, a transforma com seu trabalho; e que o resultado desta transformação, que se separa do homem, constitui seu mundo. O mundo da cultura que se prolonga no mundo da história" (FREIRE, 1983, p.44).

Diversos outros estudiosos do cinema enfatizam a importância de investir na formação das artes cinematográfica, pois sabemos que esse campo cultural necessita de uma diversificada mão de obra na produção de filmes. O cinema é uma arte coletiva e precisa de muitos profissionais envolvidos, e de atualizações constantes, uma vez que essa arte 
de fazer cinema está diretamente interligada com ciência e tecnologia, que por sua vez, se renova a cada dia, com novos equipamentos e novas ideias.

Em Noronha (2013), observamos que “As mudanças na profissão estão ocorrendo muito rapidamente e em pouco tempo diversos jovens profissionais são absorvidos pelo mercado, que muitas vezes exigem desses jovens mais do que eles estão preparados". Essa realidade no campo cinematográfico revela a importância cada mais de escolas de cinema em pleno funcionamento, para assim, suprirem a demanda do mercado de trabalho. Fatores políticos não deveriam impedir o funcionamento das duas escolas, Paulínia Magia do Cinema e Paulínia Stop Motion, localizadas no Polo Cinematográfico de Paulínia, pois sabemos das necessidades desses cursos estarem ativos, formando mão de obra qualificada para atuação no campo do cinema e, de outras áreas que também demandam profissionais com esse tipo de formação.

Palavras-chave: Escolas de Artes. Cinema. Sociedade. Educação.

\section{REFERÊNCIAS}

CATELLI, Rosana Elisa. Coleção de imagens: o cinema documentário na perspectiva da Escola Nova, entre os anos de 1920 e 1930. Campinas-SP: Revista Educ. Soc., Campinas, v. 31, n. 111, p. 605-624, jun. 2010 . Disponível em: http://dx.doi.org/10.1590/S0101-73302010000200016. Acessado em: 16 ago. 2015.

FREIRE, Paulo. Ação cultural para a liberdade. Rio de Janeiro-RJ: Ed. Paz e Terra, 1981.

Extensão ou comunicação? Rio de Janeiro-RJ: Ed. Paz e Terra, 1983.

MIGLIORIN, Cesar. O ensino de cinema e a experiência do filme-carta. Brasília-DF: Revista da Associação Nacional dos Programas de Pós-Graduação em Comunicação. Brasília, v.17, n.1, jan./abri.. 2014. Disponível em: http://www.compos.org.br/seer/index.php/e-compos/article/viewFile/1045/758.

Acessado em: 07 abr. 2015.

NORONHA, Danielle de. Ensino de cinema: os caminhos para a relação entre a formação acadêmica e a prática: Professores, alunos e profissionais falam sobre a formação em cinema e audiovisual. Rio de Janeiro-RJ: Associação Brasileira de Cinematografia-abc, artigos on-line, 06.08.2013. Disponível em: http://www.abcine.org.br/artigos/?id=1200\&/ensino-de-cinema-os-caminhos-para-arelacao-entre-a-formacao-academica-e-a-pratica. Acessado em: 05 ago. 2015.

RAMOS, Henrique de Almeida. Pensamento Computacional na Educação Básica: uma proposta de aplicação pedagógica para alunos do quinto ano do Ensino Fundamental do Distrito Federal. Brasília-DF: Universidade de Brasília-UNB, Monografia (Graduação), 2014.

Disponível em: 
http://bdm.unb.br/bitstream/10483/7720/1/2014 HenriquedeAlmeidaRamos.pdf. Acessado em: 03 ago. 2015. 